\title{
Dynamic light caused less photosynthetic suppression, rather than more, under nitrogen deficit conditions than under sufficient nitrogen supply conditions in soybean
}

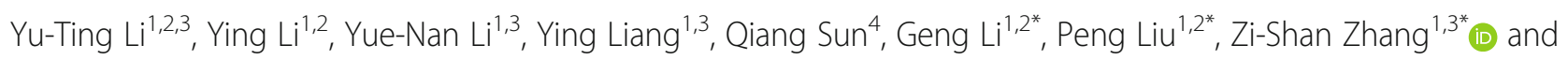
Hui-Yuan Gao ${ }^{1,3}$

\begin{abstract}
Background: Plants are always exposed to dynamic light. The photosynthetic light use efficiency of leaves is lower in dynamic light than in uniform irradiance. Research on the influence of environmental factors on dynamic photosynthesis is very limited. Nitrogen is critical for plants, especially for photosynthesis. Low nitrogen (LN) decreases ribulose-1,5-bisphosphate carboxylase/oxygenase (Rubisco) and thus limits photosynthesis. The decrease in Rubisco also delays photosynthetic induction in LN leaves; therefore, we hypothesized that the difference of photosynthetic $\mathrm{CO}_{2}$ fixation between uniform and dynamic light will be greater in $\mathrm{LN}$ leaves compared to leaves with sufficient nitrogen supply.

Results: To test this hypothesis, soybean plants were grown under low or high nitrogen (HN), and the photosynthetic gas exchange, enzyme activity and protein amount in leaves were measured under uniform and dynamic light. Unexpectedly, dynamic light caused less photosynthetic suppression, rather than more, in LN leaves than in HN leaves. The underlying mechanism was also clarified. Short low-light (LL) intervals did not affect Rubisco activity but clearly deactivated fructose-1,6-bisphosphatase (FBPase) and sedoheptulose-1,7-bisphosphatase (SBPase), indicating that photosynthetic induction after a LL interval depends on the reactivation of FBPase and SBPase rather than Rubisco. In LN leaves, the amount of Rubisco decreased more than FBPase and SBPase, so FBPase and SBPase were present in relative excess. A lower fraction of FBPase and SBPase needs to be activated in LN leaves for photosynthesis recovery during the high-light phase of dynamic light. Therefore, photosynthetic recovery is faster in LN leaves than in HN leaves, which relieves the photosynthetic suppression caused by dynamic light in LN leaves.

(Continued on next page)
\end{abstract}

\footnotetext{
*Correspondence: ligeng213@163.com; liupengsdau@126.com; zhangzishantaian@163.com

${ }^{1}$ State Key Lab of Crop Biology, Tai'an, Shandong Province, China

Full list of author information is available at the end of the article
}

(C) The Author(s). 2020 Open Access This article is licensed under a Creative Commons Attribution 4.0 International License, which permits use, sharing, adaptation, distribution and reproduction in any medium or format, as long as you give appropriate credit to the original author(s) and the source, provide a link to the Creative Commons licence, and indicate if changes were made. The images or other third party material in this article are included in the article's Creative Commons licence, unless indicated otherwise in a credit line to the material. If material is not included in the article's Creative Commons licence and your intended use is not permitted by statutory regulation or exceeds the permitted use, you will need to obtain permission directly from the copyright holder. To view a copy of this licence, visit http://creativecommons.org/licenses/by/4.0/ The Creative Commons Public Domain Dedication waiver (http://creativecommons.org/publicdomain/zero/1.0/) applies to the data made available in this article, unless otherwise stated in a credit line to the data. 
(Continued from previous page)

Conclusions: Contrary to our expectations, dynamic light caused less photosynthetic suppression, rather than more, in LN leaves than in HN leaves of soybean. This is the first report of a stress condition alleviating the photosynthetic suppression caused by dynamic light.

Keywords: Dynamic light, Low nitrogen, Photosynthesis, Soybean

\section{Background}

Plants growing under natural or semi-natural conditions are exposed to a dynamic light environment [1-3]. The light intensity on the surface of leaves varies over time scales ranging from seconds to hours. This variation is due to the movement of the sun, changes in cloud cover and shade from neighbouring plants [4-6]. Therefore, for a more comprehensive understanding of the response of photosynthesis to the environment, it is essential to characterize photosynthesis under dynamic light conditions $[2,6]$.

Compared with uniform irradiance, dynamic light decreases the light use efficiency of leaves $[1-4,7]$ due to (1) the delay in photosynthetic recovery after switching from low light (LL) to high light $(\mathrm{H})[6,8,9]$; (2) the postillumination photorespiratory $\mathrm{CO}_{2}$ burst $[6,10,11]$; and (3) the relaxation lag of nonphotochemical quenching (NPQ) after switching from HL to LL $[12,13]$. To effectively utilize the energy in dynamic light, plants need to activate photosynthesis quickly when HL conditions occur. Fast photosynthetic induction requires the rapid activation of Ribulose-1,5-bisphosphate carboxylase / oxygenase (Rubisco) and other Calvin cycle enzymes as well as the rapid opening of stomata $[2,8,14]$. The catalytic efficiency of Rubisco is relatively low, and the photosynthesis flux control value of Rubisco is much higher than the control values of other enzymes in the Calvin cycle [15]. In addition, the activation rate of $\mathrm{Ru}$ bisco is relatively slow; therefore, Rubisco is considered the limiting factor of photosynthetic induction under most conditions $[2,16]$. It has been reported that the speed of the in vivo activation of Rubisco is responsible for different photosynthetic induction rates among genotypes of soybean [17]. The activation of Rubisco is dependent on an auxiliary enzyme, Rubisco activase (RCA) [18, 19]. RCA maintains Rubisco activity by facilitating the release of inhibitory sugar molecules that impede carbamylation or catalysis [20,21]. Recent studies have reported that the amount of RCA is closely related to the photosynthetic induction rate [22], and improved RCA proteins clearly accelerate photosynthetic induction [23].

Nitrogen is one of the most important inorganic nutrients in plants. Nitrogen is crucial for plant growth, yield and especially photosynthesis, as more than $50 \%$ of total leaf nitrogen is allocated to the photosynthetic apparatus $[24,25]$. Low nitrogen (LN) supply will decrease the amount of photosynthetic pigments, thylakoid membrane proteins and Calvin cycle-related enzymes, thereby reducing photosynthetic $\mathrm{CO}_{2}$ fixation in leaves [26]. $\mathrm{Ru}$ bisco, the rate-limiting enzyme of photosynthetic $\mathrm{CO}_{2}$ fixation in $\mathrm{C} 3$ leaves under normal atmospheric $\mathrm{CO}_{2}$ conditions, is one of the proteins most sensitive to nitrogen supply levels because it is the most abundant enzyme in plant leaves and contains a large amount of nitrogen (approximately $20 \%$ of leaf nitrogen) [27].

To compensate for the decrease in Rubisco content, Rubisco activation increases in leaves with LN supply [28-32]. During photosynthetic induction, a higher Rubisco activation state will take longer to achieve in LN supply leaves. Therefore, LN supply may decelerate photosynthetic induction and thus decrease light use efficiency under dynamic light. Therefore, it was hypothesized that the difference of photosynthetic $\mathrm{CO}_{2}$ fixation between uniform and dynamic light will be greater in LN leaves compared to leaves with sufficient nitrogen supply.

To verify the above hypothesis, soybean seedlings were grown under two nitrogen supply levels. Then, the photosynthetic gas exchange, activity and amount of Calvin cycle enzyme proteins in these leaves were analysed under dynamic and uniform irradiance. Although the rhizobia that are symbiotic with soybeans can fix nitrogen, soybeans in the field still rely on the application of large amounts of fertilizer, especially during the rotation of soybeans with other crops. Nitrogen deficiency often occurs in soybean cultivation.

\section{Results \\ Photosynthetic gas exchange under steady-state light conditions}

Low N (LN) supply significantly decreased the contents of nitrogen and chlorophyll and increased the specific leaf area (SLA; Fig. 1a, b). In LN leaves, the steady-state Pn was lower than that in $\mathrm{HN}$ leaves under 150$1600 \mu \mathrm{mol} \mathrm{m}{ }^{-2} \mathrm{~s}^{-1}$ illumination (Fig. 1c). The lower PQY [33], which was estimated as the initial slope of the linear relationship between the Pn and PFD in LL leaves (Fig. 1c), indicated that the efficiency of light energy use under limited light conditions was restrained by LN supply. The Pn under saturating light $(1200-1600 \mu \mathrm{mol}$ $\mathrm{m}^{-2} \mathrm{~s}^{-1}$ ) was lower in the LN leaves than in the $\mathrm{HN}$ leaves (Fig. 1c), which indicated that the photosynthetic 

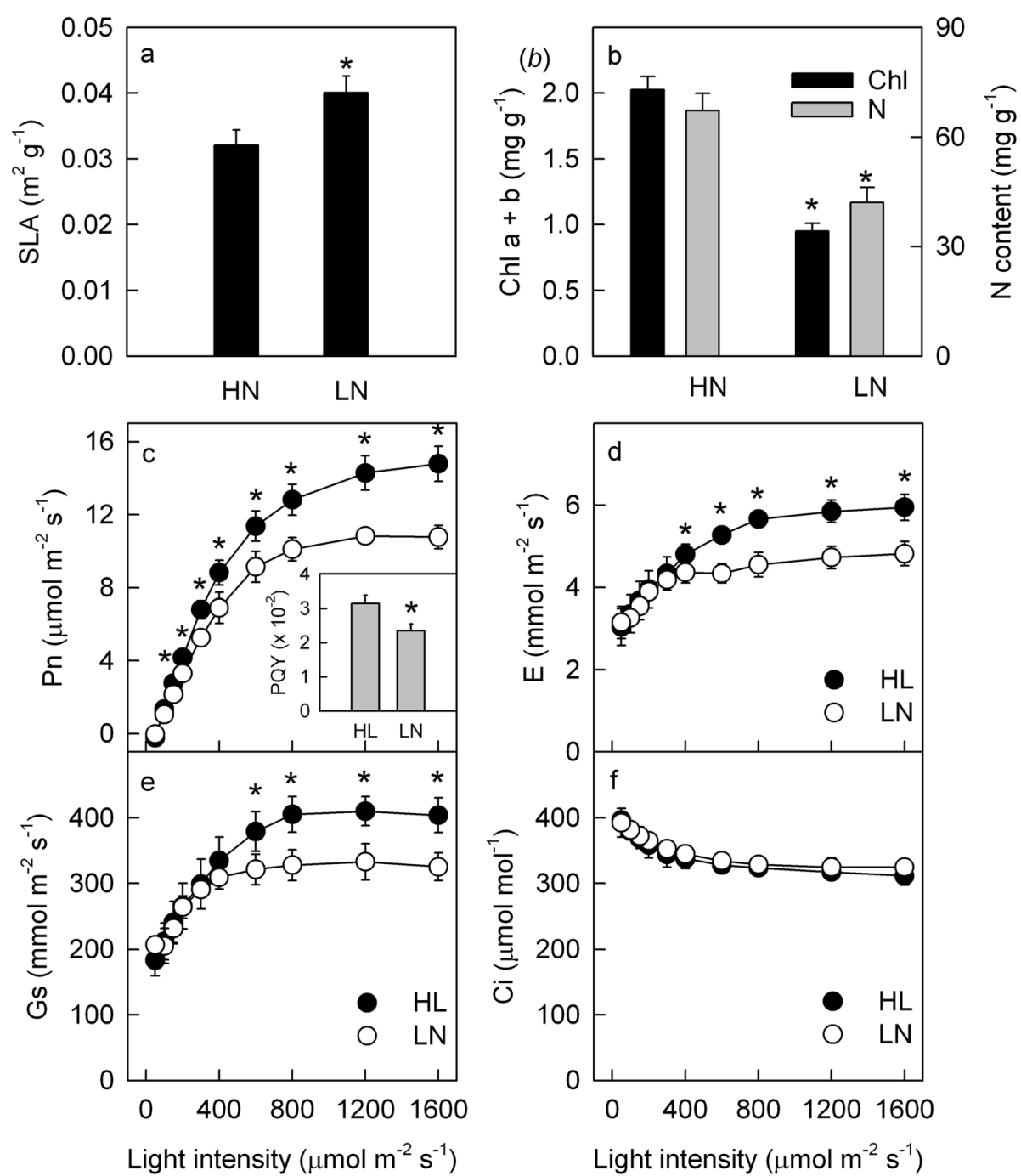

Fig. 1 Substance content and steady-state photosynthetic gas exchange. The specific leaf area (SLA; a), total chlorophyll (Chl) and nitrogen (N) contents (b), light intensity response curve of the net photosynthetic rate (Pn; $\mathbf{c}$ ), transpiration rate (E; $\mathbf{d})$, stomatal conductance (Gs; e) and intercellular $\mathrm{CO}_{2}$ concentration ( $\mathrm{Ci} ; \boldsymbol{f}$ ) as well as the photosynthetic quantum yield (PQY; plot $\mathrm{c}$ insert) in the leaves of high nitrogen (HN; filled)- and low nitrogen (LN; closed)-supplied plants. Means $\pm S D, n=6$. The asterisks indicate significant differences at $P<0.05$ between HN and LN leaves (T-test)

capacity was lower in the LN leaves. Furthermore, compared with the HN leaves, the LN leaves exhibited low stomatal conductance (Gs) and a low transpiration rate (E) but similar intercellular $\mathrm{CO}_{2}$ concentration $(\mathrm{Ci}$; Fig. 1d-f), indicating that the low Pn in the LN leaves was caused by nonstomatal limitation.

\section{Photosynthetic gas exchange under changing light conditions}

To clarify the effects of $\mathrm{N}$ supply on dynamic photosynthesis, HL-adapted $\left(1600 \mu \mathrm{mol} \mathrm{m}^{-2} \mathrm{~s}^{-1}\right)$ leaves were exposed to intervals of $\mathrm{LL}\left(100 \mu \mathrm{mol} \mathrm{m}^{-2} \mathrm{~s}^{-1}\right)$ for various durations; afterward, the LL was switched to HL (as shown in the bar above Fig. 2a), and the photosynthetic gas exchange was synchronously recorded. When the light intensity decreased, the Pn decreased quickly; however, when the light intensity increased, the Pn could not recover immediately but increased gradually (Fig. 2a, b). After a short low-light interval (60 or $120 \mathrm{~s}$ ), the Pn showed similar recovery under HL conditions in the HN and LN leaves. However, when the low-light intervals were extended to 300 or $600 \mathrm{~s}$, the subsequent recovery of Pn under $\mathrm{HL}$ in the LN leaves was faster than that in the HL leaves (Fig. 2a, b). The Pn after $30 \mathrm{~s}$ of HL exposure was used to indicate the IS\% after low-light intervals $[8,9]$. The IS\% gradually decreased with extended duration of the low-light intervals; the IS\% after a 300 or $600 \mathrm{~s}$ low-light interval was significantly lower in the $\mathrm{HN}$ leaves than in the LN leaves (Fig. 2c). 

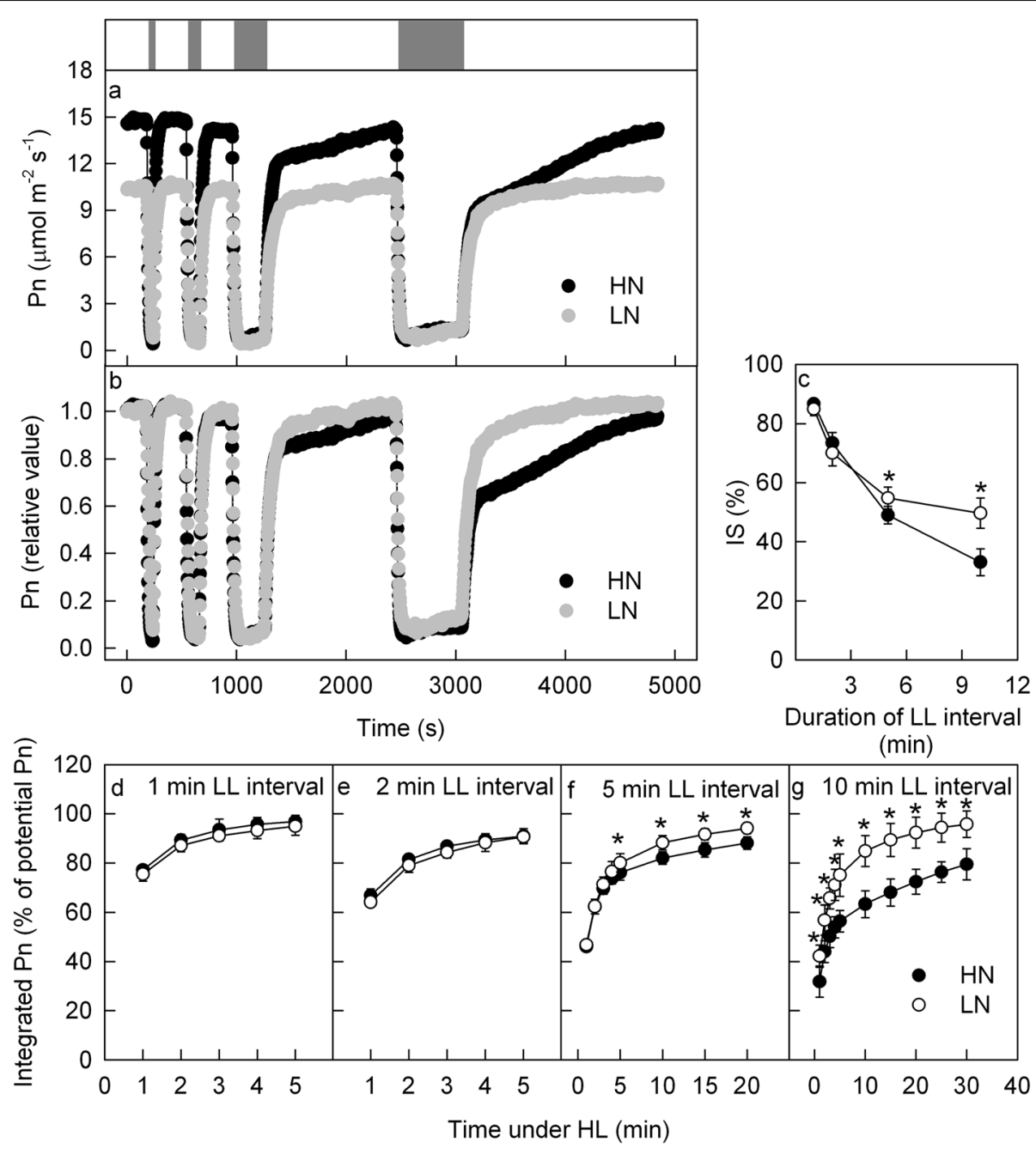

Fig. 2 Photosynthetic gas exchange under changing light conditions. The time course of the net photosynthetic rate (Pn; a, b) under changing light in the leaves of high nitrogen ( $\mathrm{HN}$; black) and low nitrogen ( $L N$; grey) supply plants. The bar above the plot (a) shows the high (1600 $\mu$ mol

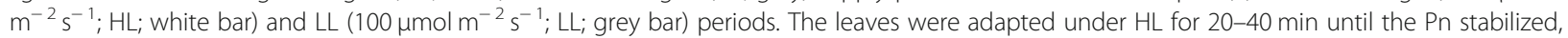
after which the leaves were exposed to changing light. The grey bars, from left to right, represent 60, 120,300, and $600 \mathrm{~s}$ of LL. The original Pn is shown in plot (a). In plot (b), the Pn under steady HL was taken as 100\%, and the Pn under changing light conditions was calculated as a percentage of the Pn under steady HL. (c) The induction state of Pn (IS\%) after LL intervals of different durations. (d-g) The integrated Pn during HL following $60(\mathbf{d}), 120$ (e), 300 ( $f$ or $600 \mathrm{~s}(\mathbf{g})$ LL intervals. Means $\pm S D, n=6$. The asterisks indicate significant differences at $P<0.05$ between HN and LN leaves (T-test)

To quantify the effects of dynamic light on photosynthetic carbon fixation, the integrated Pn during HL after various durations of low-light intervals was calculated (Fig. 2d-g). The low-light intervals caused significant losses of carbon fixation during the subsequent high-light period; this loss was aggravated by longer low-light intervals, and this loss was more severe at the beginning of the HL conditions (Fig. 2dg). The loss of photosynthetic carbon fixation after a 60 or $120 \mathrm{~s}$ low-light interval was similar between the LN and HN leaves, but the loss after a 300 or $600 \mathrm{~s}$ low-light interval was more severe in the $\mathrm{HN}$ leaves than in the LN leaves (Fig. 2d-g).
In agreement with the earlier reports [34], under changing light conditions, the Gs and $\mathrm{E}$ exhibited a similar trend to that of Pn, but the Gs and E changed more slightly and slowly than did the Pn (Additional file 1). We also observed that the Gs and E decreased more sharply in the HN leaves than in the LN leaves. The change in $\mathrm{Ci}$ was similar in the HN and the LN leaves under changing light conditions (Additional file 1), which suggested that the different dynamic Pns between the $\mathrm{HN}$ and $\mathrm{LN}$ leaves under changing light conditions were due to nonstomatal limitations.

PSII photoinhibition due to HL exposure is also a potential factor that affects $\mathrm{CO}_{2}$ fixation. Hence, the 
maximum quantum yield of PSII $(\mathrm{Fv} / \mathrm{Fm})[35,36]$ and the amounts of D1 protein, a core subunit of the PSII reaction centre in leaves [37-39], were measured before and after dynamic photosynthetic gas exchange measurement to reflect PSII photoinhibition. The dynamic photosynthetic gas exchange measurement caused a slight but significant decrease in $\mathrm{Fv} / \mathrm{Fm}$; however, the $\mathrm{Fv} / \mathrm{Fm}$ was similar in $\mathrm{LN}$ and $\mathrm{HN}$ leaves (Additional file 2). In addition, the amounts of D1 protein did not change after photosynthetic gas exchange measurement (Additional file 2). The similar Fv/Fm between $\mathrm{HN}$ and LN leaves and stable D1 protein after dynamic photosynthetic gas exchange measurement indicated that the different dynamic Pns between the HN and LN leaves were independent of PSII photoinhibition and D1 protein degradation.

Not only the $\mathrm{N}$ content but also the osmotic potential was different between the HN and LN nutrient solutions. To analyse the effect of osmotic potential on photosynthetic gas exchange, we added polyethylene glycol (PEG) to the LN nutrient solution and ensured that the osmotic potential in the LN + PEG nutrient solution was similar to the osmotic potential in the $\mathrm{HN}$ nutrient solution. The LN plant was moved to the LN + PEG nutrient solution, and the photosynthetic gas exchange in leaves was measured before and $24 \mathrm{~h}$ after moving to the LN + PEG nutrient solution. The photosynthetic gas exchange was not affected by the added PEG (Additional file 3). Therefore, the lower osmotic potential in the HN nutrient solution did not influence the photosynthetic gas exchange.

\section{Photosynthetic gas exchange under fluctuating light conditions}

The above results showed that the responses of photosynthetic gas exchange in $\mathrm{LN}$ and $\mathrm{HN}$ leaves to one short low-light interval (60 or $120 \mathrm{~s}$ ) were similar, but their responses under recurring short low-light intervals, which are common in field conditions, were unknown. To clarify this uncertainty, the leaves were exposed to light regimes that fluctuated between 100 and $1600 \mu \mathrm{mol} \mathrm{m}^{-2} \mathrm{~s}^{-1}$ every $120 \mathrm{~s}$ for a total of $32 \mathrm{~min}$ (Fig. 3a, b). It was observed that during the $120 \mathrm{~s}$ highlight period after a $120 \mathrm{~s}$ low-light interval, the Pn could not recover to the level under steady-state HL conditions, so the maximum $\mathrm{Pn}$ under the HL period $\left(\mathrm{Pn}_{\max }\right)$ gradually decreased with additional fluctuating light durations (Fig. 3c). Due to the delayed induction of Pn and the decrease in $\mathrm{Pn}_{\max }$, the integrated $\mathrm{Pn}$ was lower under fluctuating light than under steady-state light, and this loss of integrated Pn was aggravated by increased durations of fluctuating light (Fig. 3d). These decreases in $\mathrm{Pn}_{\max }$ and the integrated $\mathrm{Pn}$ under fluctuating light were more obvious in the HN leaves than in the LN leaves.
Under fluctuating light conditions, Gs and $\mathrm{E}$ decreased gradually, and the decreases in Gs and E were more severe in the $\mathrm{HN}$ leaves than in the $\mathrm{LN}$ leaves (Additional file 4). Moreover, the change in $\mathrm{Ci}$ was similar in the $\mathrm{HN}$ and $\mathrm{LN}$ leaves under fluctuating light (Additional file 4), which indicated that the different dynamic Pns between the $\mathrm{HN}$ and $\mathrm{LN}$ leaves under fluctuating light were due to nonstomatal limitations. The Fv/Fm slightly but significantly decreased after photosynthetic gas exchange measurement under fluctuating light conditions, but the decrease in $\mathrm{Fv} / \mathrm{Fm}$ was similar in $\mathrm{LN}$ and $\mathrm{HN}$ leaves, which indicated that the different dynamic Pns under fluctuating light conditions between the HN and LN leaves was independent of PSII photoinhibition.

\section{RuBP carboxylation and regeneration capacity}

The above results suggested that the difference in dynamic photosynthesis between $\mathrm{LN}$ and $\mathrm{HN}$ leaves was mostly caused by nonstomatal limitations. In addition to stomatal limitations, photosynthetic carbon fixation could be limited by biochemical factors, which include $\mathrm{RuBP}$ carboxylation and regeneration [40-42]. Therefore, the $\mathrm{Pn} / \mathrm{Ci}$ response curve was measured under saturating light $\left(1600 \mu \mathrm{mol} \mathrm{m}^{-2} \mathrm{~s}^{-1}\right)$ to quantify the RuBP carboxylation and regeneration capacity of leaves. The $\mathrm{Pn}$ was higher in the HN leaves than in the LN leaves when the Ci was lower than $600 \mu \mathrm{mol} \mathrm{mol}^{-1}$ (Fig. 4a, b), but the difference in Pn between the HN and LN leaves diminished under saturated $\mathrm{Ci}$ (Fig. 4a). The $\mathrm{V}_{\text {cmax }}$ was significantly lower in the LN leaves than in the HN leaves; however, the $\mathrm{J}_{\max }$ values in $\mathrm{LN}$ and $\mathrm{HN}$ leaves were similar (Fig. 4c, d).

The immunoblot analysis showed that the content of Rubisco, the key enzyme of RuBP carboxylation, decreased by over $50 \%$ in the LN leaves compared with the HN leaves; however, the contents of SBPase and FBPase, the key enzymes in RuBP regeneration, decreased by less than $50 \%$ in the LN leaves compared with the HN leaves (Fig. 4e). These results supported the gas exchange data in that a low $\mathrm{N}$ supply decreased the RuBP regeneration capacity more severely than the RuBP carboxylation capacity.

\section{The enzyme activity under steady and dynamic conditions}

The amount of protein reflects the potential capacity of RuBP carboxylation and regeneration in $\mathrm{LN}$ and $\mathrm{HN}$ leaves but does not reflect the actual activity of related enzymes, especially under changing light conditions. To further clarify the mechanism underlying the different dynamic photosynthesis processes between the LN and $\mathrm{HN}$ leaves, the activity levels of Rubisco, FBPase and SBPase were measured under steady and changing light conditions. Under steady $\mathrm{HL}$, the activity levels of 

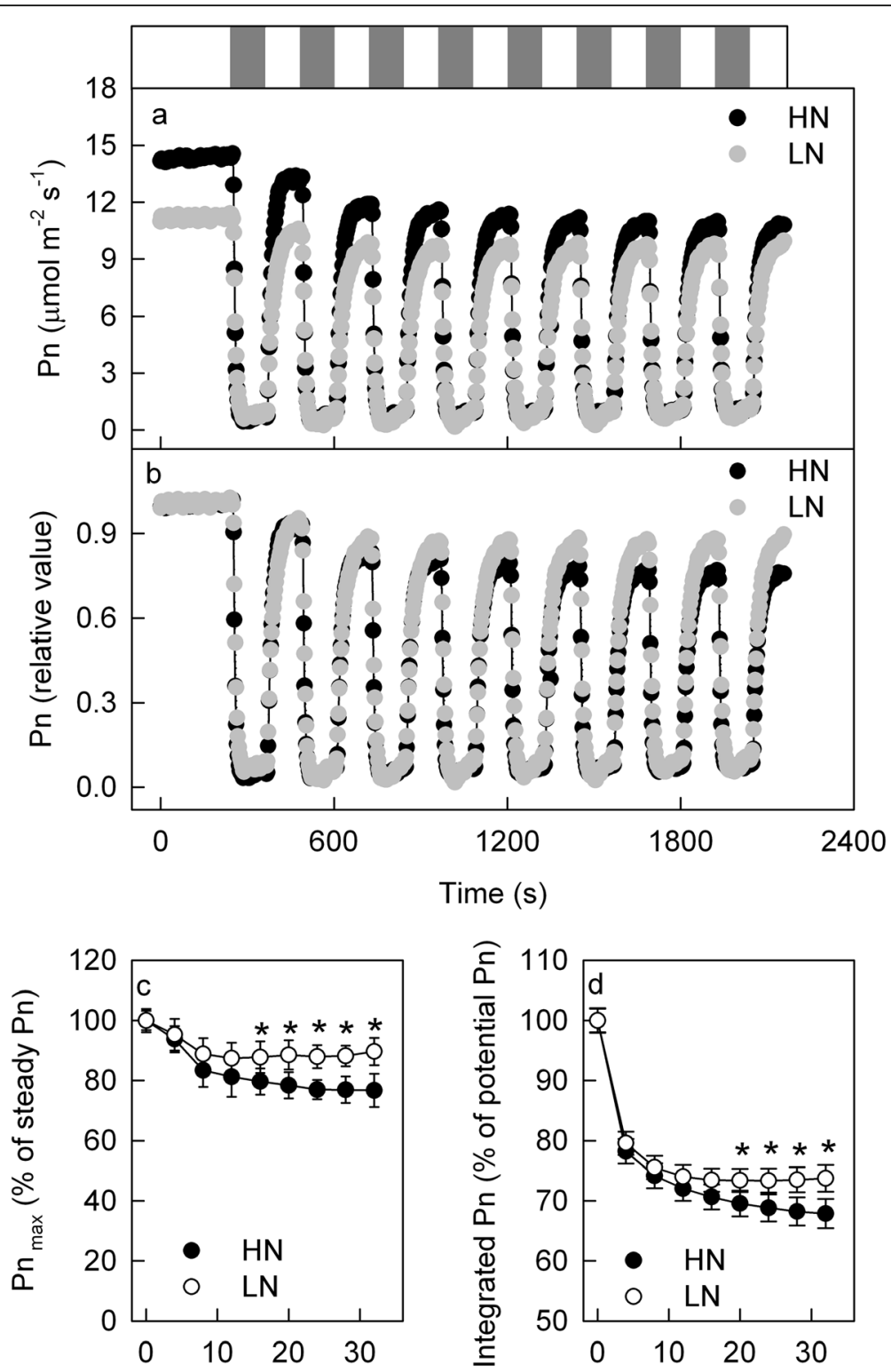

Duration of fluctuating light $(\mathrm{min})$

Fig. 3 Photosynthetic gas exchange under fluctuating light conditions. The time course of the net photosynthetic rate (Pn; $\mathbf{a}, \mathbf{b})$ under fluctuating light in the leaves of high nitrogen (HN; black) and low nitrogen (LN; grey) supply plants. The bar above the plot (a) shows the high $\left(1600 \mu \mathrm{mol} \mathrm{m} \mathrm{m}^{-2} \mathrm{~s}^{-1}\right.$; HL; white bar) and LL $\left(100 \mu \mathrm{mol} \mathrm{m} \mathrm{m}^{-2} \mathrm{~s}^{-1}\right.$; LL; grey bar) periods. The leaves were adapted under HL $\left(1600 \mu \mathrm{mol} \mathrm{m}^{-2} \mathrm{~s}^{-1}\right)$ for 20-40 min until the Pn stabilized, after which the leaves were exposed to fluctuating light such that the light intensity alternated between high $\left(1600 \mu \mathrm{mol} \mathrm{m} \mathrm{m}^{-2} \mathrm{~s}^{-1}\right)$ and low $\left(100 \mu \mathrm{mol} \mathrm{m} \mathrm{m}^{-2} \mathrm{~s}^{-1}\right)$ conditions every $120 \mathrm{~s}$. The original $\mathrm{Pn}$ is shown in plot (a). In plot (b), the Pn under steady HL was taken as 100\%, and the Pn under changing light conditions was calculated as a percentage of the Pn under steady HL. (b) The maximum Pn during the $\mathrm{HL}$ period $\left(\mathrm{Pn}_{\max }\right)$ in $\mathrm{HN}$ - and LN-supplied plants; the $\mathrm{Pn}$ under steady $\mathrm{HL}$ was taken as $100 \%$, and the $\mathrm{Pn}_{\max }$ was calculated as a percentage of the Pn under steady HL. (c) The integrated Pn during fluctuating light in HN- and LN-supplied plants. Means $\pm S D, n=6$. The asterisks indicate significant differences at $\mathrm{P}<0.05$ between $\mathrm{HN}$ and $\mathrm{LN}$ leaves (T-test)

Rubisco, FBPase and SBPase were all lower in the LN leaves than in the HN leaves, but the difference in Rubisco activity between the $\mathrm{LN}$ and $\mathrm{HN}$ leaves was more pronounced than the differences in FBPase and SBPase activity; the ratios of FBPase/Rubisco and SBPase/Rubisco activities were higher in the LN leaves than in the HN leaves (Fig. 5). After a 600 s low-light interval, the activity of Rubisco remained almost steady, but the FBPase and SBPase activity decreased to a very low level in both the LN and HN leaves (Fig. 5). Next, when the leaves were exposed again to $\mathrm{HL}$, the activity of FBPase and SBPase in the LN and HN leaves increased at the same rate. Moreover, after the leaves were exposed to 

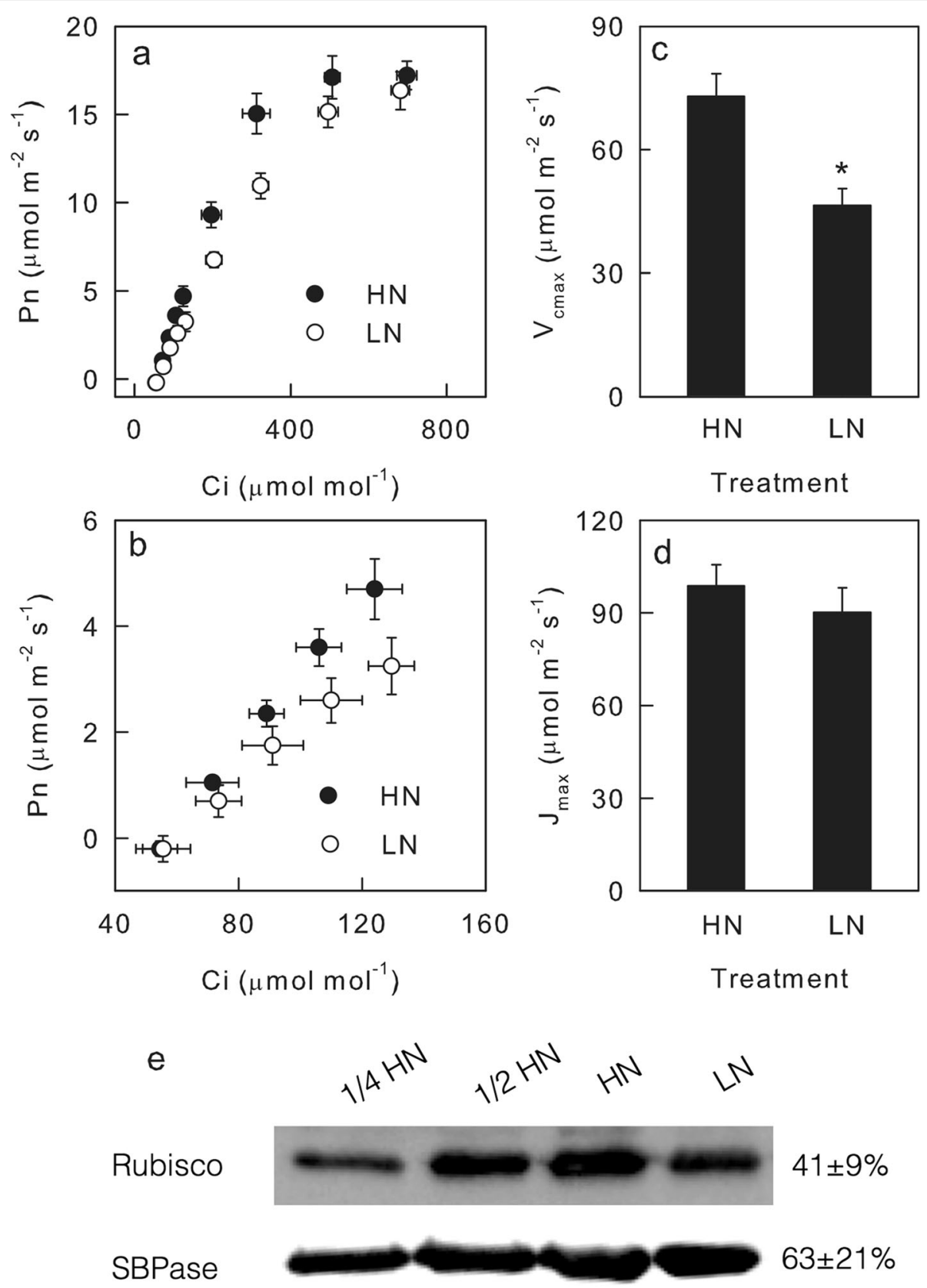

FBPase

$70 \pm 14 \%$

Fig. 4 RuBP carboxylation and regeneration capacity. The intercellular $\mathrm{CO}_{2}$ concentration (Ci) response curve of the net photosynthetic rate (Pn; $\mathbf{a}, \mathbf{b})$; the maximum rates of RuBP-carboxylation $\left(\mathrm{V}_{\mathrm{cmax}} ; \mathbf{c}\right)$; the maximum rates of RuBP regeneration $\left(\mathrm{J}_{\max }\right.$; $\left.\mathbf{d}\right)$; and the amounts of Rubisco, SBPase and FBPase (e) in the leaves of high nitrogen (HN; filled)- and low nitrogen (LN; closed)-supplied plants. In plot e, 1/2 and 1/4 indicate the quantity of protein sample loaded, and the number to the right of the bands indicates the protein content in LN leaves as a percentage of that in HN leaves. The original, full-length gel and blot were listed in Additional file 5. Means \pm SD, $n=6$ (gas exchange) or 3 (immunoblot). The asterisks indicate significant differences at $\mathrm{P}<0.05$ between $\mathrm{HN}$ and $\mathrm{LN}$ leaves (T-test)

fluctuating light for $32 \mathrm{~min}$, the Rubisco activity did not change in either the LN or HN leaves, but FBPase was deactivated in $\mathrm{HN}$ leaves more than in $\mathrm{LN}$ leaves, and SBPase was deactivated by $20.2 \%$ in $\mathrm{HN}$ leaves but only
$14.1 \%$ in LN leaves. In addition, under dynamic light conditions, the ratios of FBPase/Rubisco and SBPase/Rubisco activity were always higher in the $\mathrm{LN}$ leaves than in the $\mathrm{HN}$ leaves. 


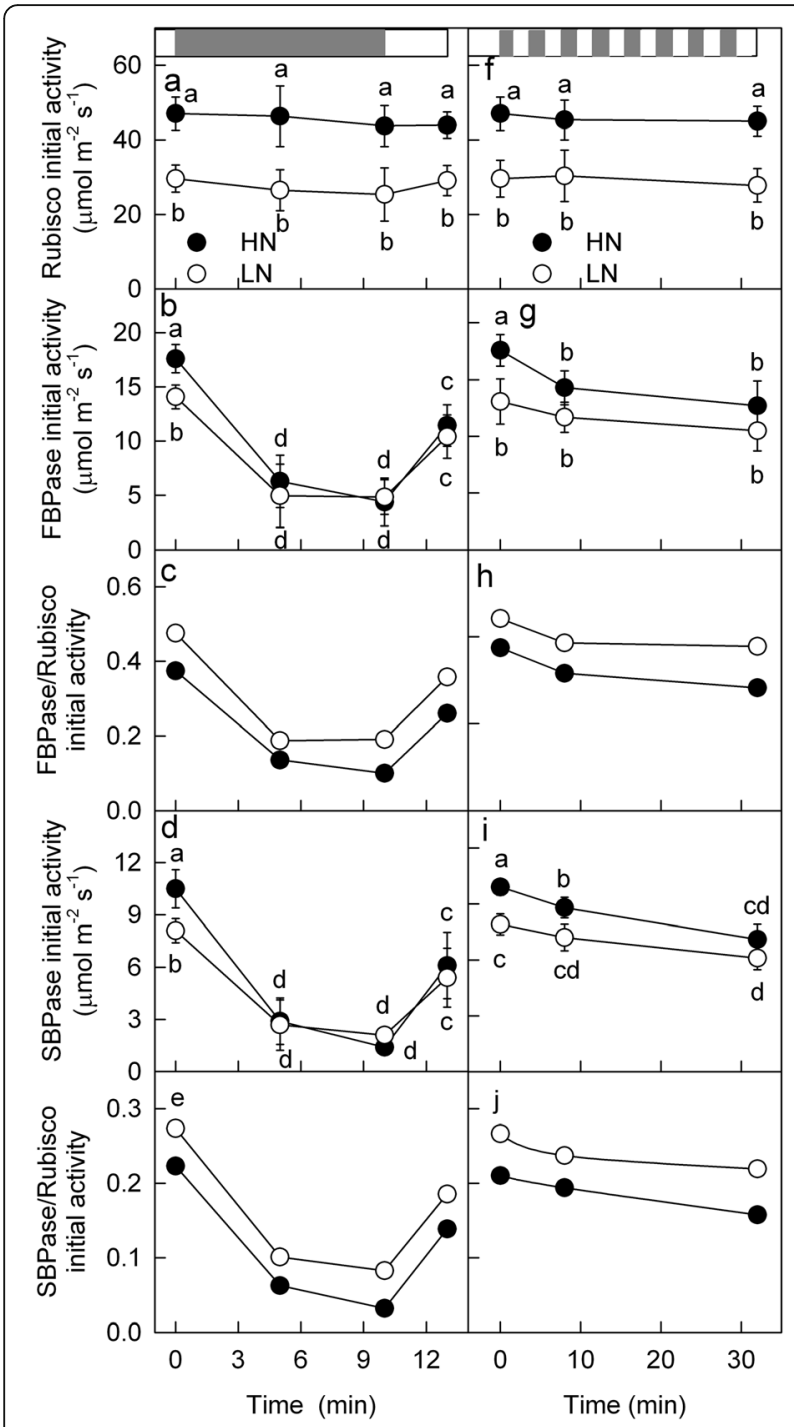

Fig. 5 Enzyme activity under steady and dynamic conditions. The activity of Rubisco $(\mathbf{a}, \mathbf{f})$, FBPase $(\mathbf{b}, \mathbf{g})$ and SBPase $(\mathbf{d}, \mathbf{i})$ as well as the ratios of activity between FBPase and Rubisco $(\mathbf{c}, \mathbf{h})$ and between SBPase and Rubisco $(\mathbf{e}, \mathbf{j})$ in the leaves of high nitrogen ( $\mathrm{HN}$; filled)and low nitrogen (LN; closed)-supplied plants under dynamic light. The bar above the plot (a) shows the high $\left(1600 \mu \mathrm{mol} \mathrm{m} \mathrm{m}^{-2} \mathrm{~s}^{-1} ; \mathrm{HL}\right.$; white bar) and $\mathrm{LL}\left(100 \mu \mathrm{mol} \mathrm{m} \mathrm{m}^{-2} \mathrm{~s}^{-1} ; \mathrm{HL}\right.$; grey bar) periods. The leaves under changing light (a-e) were adapted under $\mathrm{HL}$ for 20-40 min, and the leaves were then exposed to LL for $600 \mathrm{~s}$, after which the light was changed to HL for $180 \mathrm{~s}$. The leaves under fluctuating light (f-j) were adapted under HL for 20-40 min, after which the leaves were exposed to fluctuating light such that the light intensity alternated between high $\left(1600 \mu \mathrm{mol} \mathrm{m} \mathrm{m}^{-2} \mathrm{~s}^{-1}\right)$ and low $(100 \mu \mathrm{mol}$ $\mathrm{m}^{-2} \mathrm{~s}^{-1}$ ) every $120 \mathrm{~s}$ for $32 \mathrm{~min}$. Means $\pm S D, n=6$. Different letters indicate significant differences at $\mathrm{P}<0.05$ between different treatments (T-test)

\section{Discussion}

RuBP regeneration-related enzymes limit photosynthetic induction under dynamic light

Dynamic light consists of HL sunflecks and LL intervals between sunflecks. The fast photosynthetic activation during HL sunflecks, as well as the maintenance of the photosynthetic activation state during the LL interval, could contribute to the efficient utilization of dynamic light. Therefore, both enzymes that are activated slowly under HL sunflecks and enzymes whose activity decreases rapidly during LL intervals are potential limiting factors for optimizing photosynthesis under dynamic light conditions.

One 600 s LL interval or recurring shorter (120s) LL intervals interfered only slightly with Rubisco activity but markedly reduced the activity of FBPase and SBPase (Fig. 5), which is consistent with the faster reduction and oxidation of FBPase proteins under light and dark conditions, respectively [43]. Next, when HL suddenly appears, Rubisco is still highly active, but SBPase and FBPase need to be reactivated to match the activity of Rubisco. Therefore, photosynthetic induction after an LL interval is limited mainly by the reactivation of SBPase and FBPase.

SBPase and FBPase were almost completely deactivated after a $10 \mathrm{~min}$ LL interval (Fig. 5), so a longer LL interval will not continue deactivating SBPase and FBPase. However, the activity of Rubisco will continue to decrease if the duration of the LL interval is extended. Therefore, we presume that the limitation of Rubisco activation state to photosynthetic induction will increase with the extension of LL interval.

In addition to SBPase and FBPase, which were measured in this experiment, GAPDH and PRK are also light-activated enzymes and potential rate-limiting enzymes in RuBP regeneration [15], though their photosynthetic flux control values are lower than those of SBPase and FBPase [15]. Both in vitro and in vivo experiments have shown that the GAPDH and PRK enzymes were activated very quickly but inactivated slowly [4446], even under only $300 \mu \mathrm{mol} \mathrm{m}^{-2} \mathrm{~s}^{-1}$ [41]. However, opposite results were also reported [47]. Moreover, some nonregulated enzymes that catalyse reversible reactions, such as aldolase and transketolase, exert significant control over carbon flux under steady-state light [15, 4850]. Therefore, the roles of other Calvin cycle-related enzymes in photosynthetic induction under dynamic light require further study.

Recent studies have reported that redundant NPQ can decrease photosynthetic electron transport and thus restrict $\mathrm{CO}_{2}$ fixation under dynamic light conditions [12, 51]. However, we think the difference in dynamic photosynthesis between LN and HN soybean leaves was not contributed by the NPQ itself because electron transport is the limiting factor of $\mathrm{CO}_{2}$ fixation only under low light and not under high light; thus, NPQ influenced electron transport and therefore changed $\mathrm{CO}_{2}$ fixation after the conversion from high to low light rather than after the conversion from low to high light $[12,51]$. The 
different $\mathrm{CO}_{2}$ fixation behaviours between $\mathrm{LN}$ and $\mathrm{HN}$ leaves were observed only after the conversion from low to high light (Figs. 2, 3), so this difference was not caused by NPQ.

\section{The dynamic light-induced photosynthetic suppression is less, rather than more, in LN leaves than in HN soybean leaves}

Like steady-state photosynthesis, dynamic photosynthesis can also be influenced by environmental factors. The relationship between steady-state photosynthesis and the environment has been extensively researched; however, there are only a limited number of studies related to the influence of environmental factors on dynamic photosynthesis [2]. Generally, stress conditions will increase the photosynthetic suppression caused by dynamic light, and favourable conditions will alleviate the effect. It was reported that drought [9], nitrogen deficiency [8] and heat stress [52] all increased the photosynthetic suppression caused by dynamic light. In addition, the dynamic light-induced photosynthetic suppression was alleviated by a high $\mathrm{CO}_{2}$ atmosphere [10, 53-56]. However, our results showed that dynamic light-induced photosynthetic suppression was alleviated rather than exacerbated by LN stress. As far as we know, this research is the first to report that a stress condition alleviates the photosynthetic suppression caused by dynamic light.

This result was outside our expectations. According to traditional viewpoints [9], the activation state of Rubisco will increase to compensate for the decreased amount of Rubisco in LL supply leaves; a higher Rubisco activation state will take longer to achieve, which will delay photosynthetic induction and therefore increase the photosynthetic suppression caused by dynamic light.

However, this study indicated that photosynthetic induction after the LL interval is limited mainly by the reactivation of SBPase and FBPase rather than by Rubisco (see above). Therefore, although the content of Rubisco decreased significantly in LN supply leaves (Figs. 4, 5), this decrease did not delay photosynthetic induction after LL intervals. In addition, because the amount of Rubisco decreased more obviously than the amounts of SBPase and FBPase (Fig. 4), SBPase and FBPase were present in relative excess in LN leaves (Fig. 5). Therefore, a lower fraction of SBPase and FBPase was required for activation (Fig. 5), and thus, a shorter time was needed in the LN leaves to match the activity of Rubisco during photosynthetic induction after LL intervals. Consequently, photosynthetic induction was faster in LN supply leaves than in $\mathrm{HN}$ supply leaves, alleviating the dynamic lightinduced photosynthetic suppression.

\section{Conclusions}

This study suggests that the reactivation of RuBP regeneration-related enzymes (SBPase and FBPase), rather than RuBP carboxylation enzyme (Rubisco), limits photosynthetic induction and light use efficiency under dynamic light. Excess FBPase and SBPase relative to $\mathrm{Ru}-$ bisco in LN soybean leaves accelerated photosynthetic induction under dynamic light. Therefore, contrary to our expectations, dynamic light caused less photosynthetic suppression, rather than more, in LN leaves than in $\mathrm{HN}$ soybean leaves.

\section{Methods}

\section{Plant materials}

Soybean (Glycine max cv. Qihuang34; purchased from Crop Research Institute, Shandong Academy of Agricultural Sciences) undertook the formal identification. The seeds are still sold commercially, but it is not clear whether the voucher specimen has been deposited in a publicly available herbarium. Plants were grown in pots (20 cm in diameter, $25 \mathrm{~cm}$ in height) filled with vermiculite. Nutrient solutions with high (10 $\mathrm{mM}$ nitrate) or low (1 mM nitrate) nitrogen were used to irrigate plants every 2 days. The nutrient solution contained 1 or 10 $\mathrm{mM} \mathrm{N}, 10 \mathrm{mM} \mathrm{P}, 25 \mathrm{mM} \mathrm{K}, 2 \mathrm{mM} \mathrm{Mg}, 1 \mathrm{mM} \mathrm{Ca}, 2 \mathrm{mM}$ S, $0.1 \mathrm{mM} \mathrm{Fe}, 180 \mu \mathrm{M} \mathrm{B}, 25 \mu \mathrm{M}$ Mn, $3 \mu \mathrm{M} \mathrm{Zn}, 1.3 \mu \mathrm{M}$ $\mathrm{Cu}$, and $0.5 \mu \mathrm{M}$ Mo. Not only nitrogen deficiency but also excess nitrogen is harmful to plants, including the photosynthetic mechanism. The $10 \mathrm{mM}$ nitrate used as "high nitrogen treatment" in this study has been referred to in previous reports in soybean $[57,58]$ and other species [59-62] as supplying sufficient but not excess nitrogen to plants.

The different levels of nitrogen supply also affect the osmotic potential of the nutrient solutions, but this mild increase in the osmotic potential of high nitrogen (HN) nutrient solutions can be neglected. Soil was not used during growth, and nodulation was not observed during the experiment. The plants were placed in a greenhouse; the maximum temperature and light intensity were approximately $32{ }^{\circ} \mathrm{C}$ and $1000 \mu \mathrm{mol} \mathrm{m}^{-2} \mathrm{~s}^{-1}$ during the day. The humidity in the greenhouse was $50-70 \%$. The youngest fully developed leaves of 4- to 5-week-old plants were used for the experiments.

\section{SLA, nitrogen and chlorophyll content}

The specific leaf area (SLA) was calculated by dividing the leaf area by the leaf dry mass. The leaf area was measured using an LI-3000C Area Meter (Li-Cor, USA), and then the leaf material was dried at $70^{\circ} \mathrm{C}$. The leaf chlorophyll was extracted with $80 \%$ acetone from frozen leaves, and the extracts were analysed with a UV-2550 spectrophotometer (Shimadzu, Japan) in accordance with the methods of Porra et al. [63]. The total nitrogen 
content was measured with a K9860 automatic Kjeldahl apparatus (Hanon, China).

\section{Gas exchange measurements}

The photosynthetic gas exchange parameters, photosynthetic rate $(\mathrm{Pn})$, transpiration rate $(\mathrm{E})$ and substomatal $\mathrm{CO}_{2}$ concentration $(\mathrm{Ci})$ were measured using a CIRAS-3 portable photosynthesis system (PP Systems, USA). The light intensity, light quality ( $95 \%$ red and $5 \%$ blue light), $\mathrm{CO}_{2}$ partial pressure $(\mathrm{Cr})$, relative humidity $(60 \%)$ and leaf temperature $\left(30^{\circ} \mathrm{C}\right)$ were controlled by an automatic control device in the CIRAS-3 photosynthesis system. Before the photon flux density (PFD) and $\mathrm{CO}_{2}$ response curve measurements, the leaves were adapted to $\mathrm{HL}$ $\left(1600 \mu \mathrm{mol} \mathrm{m}^{-2} \mathrm{~s}^{-1}\right)$ and normal $\mathrm{CO}_{2}\left(400 \mu \mathrm{mol} \mathrm{mol}^{-1}\right)$ conditions, and they were then adapted to each light intensity and $\mathrm{CO}_{2}$ concentration for at least $120 \mathrm{~s}$ during the response curve measurements. The light intensities were altered in the following order during the measurement of the PFD response curve: 1600, 1200, 800, 600, 400, 300, 200, 150, 100, and $50 \mu \mathrm{mol} \mathrm{m}^{-2} \mathrm{~s}^{-1}$. The $\mathrm{Cr}$ was altered in the following order during the measurement of the $\mathrm{CO}_{2}$ response curve: 400, 300, 200, 175, $150,125,100,400,600$, and $800 \mu \mathrm{mol} \mathrm{mol}^{-1}$. The photosynthetic quantum yield (PQY) was estimated as the slope of the linear relationship between Pn and light intensity under LL $\left(50-200 \mu \mathrm{mol} \mathrm{m}^{-2} \mathrm{~s}^{-1}\right)$ [33]. Measurements for the $\mathrm{Pn} / \mathrm{Ci}$ response curves were made starting at $400 \mu \mathrm{mol} \mathrm{mol}^{-1}$ ambient $\mathrm{CO}_{2}$ and then decreased stepwise to $50 \mu \mathrm{mol} \mathrm{mol}^{-1}$; afterward, the concentration was returned to $400 \mu \mathrm{mol} \mathrm{mol}^{-1}$ and maintained for at least $15 \mathrm{~min}$ until the $\mathrm{Pn}$ was restored to the initial value to reactivate Rubisco, and then, the ambient $\mathrm{CO}_{2}$ concentration was gradually increased from 400 to $900 \mu \mathrm{mol} \mathrm{mol}^{-1}$. The $\mathrm{CO}_{2}$ assimilation rate is limited either by RuBP carboxylation or by RuBP regeneration according to the C3 photosynthesis model [40]. The maximum rates of RuBP-carboxylation $\left(\mathrm{V}_{\mathrm{cmax}}\right)$ and RuBP-regeneration $\left(\mathrm{J}_{\max }\right)$ were calculated by fitting the $\mathrm{Pn} / \mathrm{Ci}$ response curves $[64,65]$. A typical value for mitochondrial respiration rates in the light $(\mathrm{Rd})$, the Michaelis constant of Rubisco for carbon dioxide and the $\mathrm{CO}_{2}$ compensation point in the absence of respiration $\left(1.35 \mu \mathrm{mol} \mathrm{m}^{-2} \mathrm{~s}^{-1}, \quad 651 \mu \mathrm{mol} \mathrm{mol}^{-1}\right.$, and $55.2 \mu \mathrm{mol}$ $\mathrm{mol}^{-1}$, respectively) [65] were used to solve the values of $\mathrm{V}_{\mathrm{cmax}}$ and $\mathrm{J}_{\max }$ in this study.

To measure dynamic gas exchange under changing light conditions, the leaves were light adapted under $1600 \mu \mathrm{mol} \mathrm{m}^{-2} \mathrm{~s}^{-1}$ light and $400 \mu \mathrm{mol} \mathrm{mol}^{-1} \mathrm{CO}_{2}$ in the chamber of the CIRAS-3. After the photosynthetic gas exchange reached a steady state, the data were automatically recorded by the CIRAS-3 every $3 \mathrm{~s}$. The light intensity on the surface of leaves was controlled by an automatic control device on the CIRAS-3 according to one of two protocols used in this study. The first one was as follows: $180 \mathrm{~s}$ of $\mathrm{HL}\left(1600 \mu \mathrm{mol} \mathrm{m}^{-2} \mathrm{~s}^{-1}\right), 60 \mathrm{~s}$ of LL $\left(100 \mu \mathrm{mol} \mathrm{m}^{-2} \mathrm{~s}^{-1}\right), 300 \mathrm{~s}$ of HL, $120 \mathrm{~s}$ of LL, $300 \mathrm{~s}$ of $\mathrm{HL}, 300 \mathrm{~s}$ of LL, $1200 \mathrm{~s}$ of HL, $600 \mathrm{~s}$ of LL, and then $1800 \mathrm{~s}$ of HL. The second protocol was as follows: $240 \mathrm{~s}$ of HL followed by LL and HL alternating every $120 \mathrm{~s}$. In this study, the area below the time course curve of the gas exchange represents the integrated gas exchange. The induction state (IS\%) value of $\mathrm{Pn}$ was calculated as $I S \%=\left(P_{30 s}+R_{d}\right) /\left(P_{\text {steady }}+R_{d}\right)$, where $P_{30 s}$ is the $P n$ after $30 \mathrm{~s}$ of $\mathrm{HL}$ following an interval of LL, $\mathrm{Pn}_{\text {steady }}$ is the Pn under steady-state HL conditions, and $R_{d}$ is the respiratory rate in darkness.

\section{Immunoblot analysis}

After steady-state gas exchange measurements, the leaves were cut, weighed and immediately stored in liquid nitrogen. The soluble proteins were extracted with a buffer consisting of $50 \mathrm{mM}$ HEPES-KOH (pH 7.8), 10 $\mathrm{mM} \mathrm{NaCl}$, and $2 \mathrm{mM} \mathrm{MgCl} 2$ from $1.75 \mathrm{~cm}^{-2}$ of leaf tissue. Ten microliters of soluble proteins were mixed with loading buffer and degenerated at $99^{\circ} \mathrm{C}$ for $10 \mathrm{~min}$. The soluble proteins were then loaded onto and separated on a $10 \%(w / w)$ SDS-PAGE gel. Proteins from the gel were subsequently blotted onto nitrocellulose using standard methods. Immunodetection was carried out via specific primary antibodies and horseradish peroxidase-conjugated anti-rabbit secondary antibodies (Solarbio, China). A Thermo Scientific SuperSignal West Pico substrate was applied for the detection of the immunoreaction. The chemiluminescence was recorded on blots via a Tanon 5500 cooled charge-coupled device camera (Tanon, China). The primary antibodies against fructose-1,6bisphosphatase (FBPase), sedoheptulose-1,7-bisphosphatase (SBPase) and the Rubisco large subunit (RbcL) were purchased from Phyto AB (USA) or Agrisera (Sweden).

\section{Determination of enzyme activity}

The enzyme activity and gas exchange were analysed in different plants. Before illumination, the leaf area was measured by an LI-3000C Area Meter (Li-Cor, USA). After illumination, the leaves were isolated from the plants and quickly frozen in liquid nitrogen. The Rubisco activity was determined in accordance with the methods of Yang et al. and Cheng et al. $[66,67]$. The frozen leaf discs were ground to a fine powder in liquid nitrogen using a mortar and pestle in extraction buffer containing $100 \mathrm{mM}$ tricine (pH 8.0), $5 \mathrm{mM} \mathrm{MgCl}_{2}, 0.1 \mathrm{mM}$ EDTA, $5 \mathrm{mM}$ dithiothreitol, $1 \%(\mathrm{w} / \mathrm{v})$ polyvinylpyrrolidone, $1 \%(\mathrm{w} / \mathrm{v})$ casein and $0.05 \%(\mathrm{v} / \mathrm{v})$ Triton X-100. The initial Rubisco activity was measured in reaction medium containing $5 \mathrm{mM}$ HEPES$\mathrm{NaOH}$ (pH 8.0), $1 \mathrm{mM} \mathrm{NaHCO}, 2 \mathrm{mM} \mathrm{MgCl}, 0.25 \mathrm{mM}$ dithiothreitol, $0.1 \mathrm{mM}$ EDTA, $1 \mathrm{U}$ of glyceraldehyde-3phosphate dehydrogenase, $0.5 \mathrm{mM} \quad$ ATP,$\quad 0.015 \mathrm{mM}$ 
$\mathrm{NADH}_{2}, 0.5 \mathrm{mM}$ phosphocreatine, and $0.06 \mathrm{mM}$ ribulose1,5-bisphosphate. The change in absorbance at $340 \mathrm{~nm}$ was monitored for $90 \mathrm{~s}$. The SBPase activity was determined in accordance with the methods of Harrison et al. and Simkin et al. [68, 69]. The extraction buffer containing $50 \mathrm{mM}$ HEPES (pH 8.2), $5 \mathrm{mM} \mathrm{MgCl}_{2}, 1$ mM EDTA, $1 \mathrm{mM}$ EGTA, 10\% glycerol, 0.1\% Triton $\mathrm{X}-100,2 \mathrm{mM}$ benzamidine, $2 \mathrm{mM}$ amino caproic acid, $0.5 \mathrm{mM}$ phenylmethanesulfonyl fluoride (PMSF), and $10 \mathrm{mM}$ dithiothreitol (DTT).

reaction medium containing $50 \mathrm{mM}$ Tris ( $\mathrm{pH} 8.2), 15$ $\mathrm{mM} \mathrm{MgCl}_{2}, 1.5 \mathrm{mM}$ EDTA, $10 \mathrm{mM}$ DTT, and $2 \mathrm{mM}$ sedoheptulose-1,7-bisphosphate and extracts, the analysing before after $5 \mathrm{~min}$ incubation at $25^{\circ} \mathrm{C}$. The reaction was stopped by the addition of perchloric acid solution and then centrifuged at $4{ }^{\circ} \mathrm{C}$. The samples and standards were mixed with Biomol Green (Affiniti Research Products, Exeter, UK) and then incubated for $30 \mathrm{~min}$ at room temperature before the absorbance at $620 \mathrm{~nm}$ was measured. The FBPase activity was determined according to the method of Sassenrath-Cole and Pearcy [45]. The extraction buffer containing $100 \mathrm{mM}$ tricine $(\mathrm{pH} 8.1), 10$ $\mathrm{mM} \mathrm{MgCl} 2,1 \mathrm{mM}$ EDTA, $15 \mathrm{mM}$ mercaptoethanol, and $1 \mathrm{mM}$ fructose-1,6-bisphosphate. The FBPase activity was determined at $25^{\circ} \mathrm{C}$ by measuring the increase in absorbance at $340 \mathrm{~nm}$ in $1 \mathrm{~mL}$ of assay buffer containing $100 \mathrm{mM}$ tricine (pH 8.1), $20 \mathrm{mM} \mathrm{MgCl}_{2}, 1 \mathrm{mM}$ EDTA, $0.3 \mathrm{mM} \mathrm{NADP}^{+}, 0.6 \mathrm{mM}$ fructose-1,6-bisphosphate, 0.6 units of glucose-6-P-dehydrogenase, 1.2 units of phosphoglucoisomerase and $0.1 \mathrm{~mL}$ of leaf extract. Some cytosolic FBPase activity will be detected despite using assay conditions to favour plastid FBPase. However, it was reported that the activity of cytosolic FBPase is only less than $1.2 \%$ of the activity of plastid FBPase in Arabidopsis leaves under light [70]. Therefore, the contribution of cytosolic FBPase to the FBPase activity was neglected. The activity of FBPase detected by the above assay conditions was considered plastid FBPase.

\section{Statistical analysis}

The measurements were performed in 3-6 plants. Ttests were used to analyse differences between the treatments using SPSS 11.

\section{Supplementary information}

Supplementary information accompanies this paper at https://doi.org/10. 1186/s12870-020-02516-y.

Additional file 1: Figure S1. The stomatal conductance (Gs), transpiration rate $(\mathrm{E})$ and the substomatal $\mathrm{CO}_{2}$ concentration (Ci) under changing light conditions.

Additional file 2: Figure S2. The PSII photoinhibition caused by the mensuration of dynamic photosynthetic gas exchange.

Additional file 3: Figure S3. The effect of osmotic potential on photosynthetic gas exchange.
Additional file 4: Figure S4. The stomatal conductance (Gs), transpiration rate $(\mathrm{E})$ and substomatal $\mathrm{CO}_{2}$ concentration (Ci) under fluctuating light conditions.

Additional file 5: Figure S5. The original, full-length gel and blot of Rubisco, SBPase and FBPase.

Additional file 6. raw data of Fig. 1-5 and Fig. S1-S4.

\section{Abbreviations}

Ci: Substomatal $\mathrm{CO}_{2}$ concentration; $\mathrm{Cr}$ : $\mathrm{CO}_{2}$ partial pressure; $\mathrm{E}$ : Transpiration rate; FBPase: Fructose-1,6-bisphosphatase; HL: High light; HN: High nitrogen; IS\%: Induction state of $\mathrm{Pn}$; I $\mathrm{max}_{\text {ax }}$ Maximum rates of RuBP-regeneration; LL: Low light; LN: Low nitrogen; PEG: Polyethyleneglycol; PFD: Photon flux density; $\mathrm{Pn}$ : Photosynthetic rate; $\mathrm{Pn}_{\text {max }}$ : Maximum $\mathrm{Pn}$ under the $\mathrm{HL}$ period; PQY: Photosynthetic quantum yield; RbcL: RUBISCO large subunit; RCA: Rubisco activase; Rd: Mitochondrial respiration rates in the light; Rubisco: Ribulose-1,5-bisphosphate carboxylase/oxygenase;

SBPase: Sedoheptulose-1,7- bisphosphatase; SLA: Specific leaf area; $\mathrm{V}_{\text {cmax }}$ : Maximum rates of RuBP-carboxylation

\section{Acknowledgements}

Not applicable.

\section{Authors' contributions}

YTL and YNL carried out most of the experiments and data analysis. YL2 cultivate plants. QS analyzed enzyme activity. GL, PL, ZSZ designed the study. YL1, ZSZ and HYG were major contributors in writing the manuscript. All authors read and approved the final manuscript.

\section{Funding}

This work was financially supported by National Natural Science Foundation of China (31701966; 31401339; 31771691); Shandong Provincial Natural Science Foundation, China (ZR2017QC001); National Key Research and Development Program of China (2016YFD0300106; 2016YFD0300205).

Moreover, the funders had no role in the design of the study and collection, analysis and interpretation of data, decision to publish, or the preparation of the manuscript.

\section{Availability of data and materials}

All data generated or analysed during this study are included in this published article [and its supplementary information files].

Ethics approval and consent to participate

Not applicable.

Consent for publication

Not applicable.

Competing interests

The authors declare that they have no competing interests.

\section{Author details}

${ }^{1}$ State Key Lab of Crop Biology, Tai'an, Shandong Province, China. ${ }^{2}$ College of Agronomy, Shandong Agricultural University, Tai'an, Shandong Province, China. ${ }^{3}$ College of Life Sciences, Shandong Agricultural University, Tai'an, Shandong Province, China. ${ }^{4}$ Tai'an Testing Center For Food And Drug Control, Tai'an, Shandong Province, China.

Received: 30 November 2019 Accepted: 23 June 2020

Published online: 17 July 2020

\section{References}

1. Pearcy RW. Sunflecks and photosynthesis in plant canopies. Annu Rev Plant Physiol. 1990;41:421-53.

2. Way DA, Pearcy RW. Sunflecks in trees and forests: from photosynthetic physiology to global change biology. Tree Physiol. 2012;32:1066-81.

3. Petridis A, van der Kaay J, Chrysanthou E, McCallum S, Graham J, Hancock RD. Photosynthetic limitation as a factor influencing yield in highbush blueberries (Vaccinium corymbosum) grown in a northern European environment. J Exp Bot. 2018;69:3069-80. 
4. Leakey ADB, Press MC, Scholes JD. Patterns of dynamic irradiance affect the photosynthetic capacity and growth of dipterocarp tree seedlings. Oecologia. 2003;135:184-93.

5. Zhu XG, Ort DR, Whitmarsh J, Long SP. The slow reversibility of photosystem ii thermal energy dissipation on transfer from high to low light may cause large losses in carbon gain by crop canopies: a theoretical analysis. J Exp Bot. 2004;55:1167-75.

6. Kaiser E, Morales A, Harbinson J, Kromdijk J, Heuvelink E, Marcelis LF. Dynamic photosynthesis in different environmental conditions. J Exp Bot. 2015;66:2415-26

7. Timm HC, Stegemann J, Kuppers M. Photosynthetic induction strongly affects the light compensation point of net photosynthesis and coincidentally the apparent quantum yield. Trees. 2002;16:47-62.

8. Sun J, Miao Y, Peng S, Yong L. Nitrogen can improve the rapid response of photosynthesis to changing irradiance in rice (Oryza sativa L.) plants. Sci Rep. 2016;6:31305

9. Sun J, Zhang Q, Tabassum MA, Ye M, Peng S, Li Y. The inhibition of photosynthesis under water deficit conditions is more severe in flecked than uniform irradiance in rice (Oryza sativa) plants. Funct Plant Bio. 2017;44: 464-72.

10. Leakey ADB, Press MC, Scholes JD, Watling JR. Relative enhancement of photosynthesis and growth at elevated $\mathrm{CO}_{2}$, is greater under sunflecks than uniform irradiance in a tropical rain forest tree seedling. Upon photosynthesis and growth under sunflecks. Plant Cell Environ. 2002;25: $1701-14$.

11. Leakey ADB, Scholes JD, Press MC. Physiological and ecological significance of sunflecks for dipterocarp seedlings. J Exp Bot. 2005;56:469-82.

12. Kromdijk J, Głowacka K, Leonelli L, Gabilly ST, Iwai M, Niyogi KK, Long SP. Improving photosynthesis and crop productivity by accelerating recovery from photoprotection. Science. 2016:354:857-61.

13. Hubbart S, Smillie IR, Heatley M, Swarup R, Foo CC, Zhao L, Murchie EH. Enhanced thylakoid photoprotection can increase yield and canopy radiation use efficiency in rice. Commun Bio. 2018;1:22.

14. Porcar-Castell A, Palmroth S. Modelling photosynthesis in highly dynamic environments: the case of sunflecks. Tree Physiol. 2012;32:1062-5.

15. Raines CA. The Calvin cycle revisited. Photosynth Res. 2003;75:1-10.

16. Seemann JR, Sharkey TD, Pearcy RW. Regulation of ribulose-1,5bisphosphate carboxylase activity in alocasia macrorrhiza in response to step changes in irradiance. Plant Physiol. 1988;88:148-52.

17. Soleh MA, Tanaka Y, Nomoto Y, Iwahashi Y, Nakashima K, Fukuda Y, et al. Factors underlying genotypic differences in the induction of photosynthesis in soybean (Glycine max (I.) Merr.). Plant Cell Environ. 2016;39:685-93.

18. Portis AR. Rubisco activase - rubisco's catalytic chaperone. Photosynth Res. 2003;75:11-27

19. Carmo-Silva E, Scales JC, Madgwick PJ, Parry MA. Optimizing rubisco and its regulation for greater resource use efficiency. Plant Cell Environ. 2015;38: $1817-32$

20. Portis AR. Regulation of ribulose 1,5-bisphosphate carboxylase/oxygenase activity. Annu Rev Plant Biol. 1992:43:415-37.

21. Hauser T, Popilka L, Hartl FU, Hayer-Hartl M. Role of auxiliary proteins in Rubisco biogenesis and function. Nat Plants. 2015;1:15065.

22. Yamori W, Masumoto C, Fukayama H, Makino A. Rubisco activase is a key regulator of non-steady-state photosynthesis at any leaf temperature and, to a lesser extent, of steady-state photosynthesis at high temperature. Plant J. 2012;71:871-80.

23. Carmo-Silva AE, Salvucci ME. The regulatory properties of rubisco activase differ among species and affect photosynthetic induction during light transitions. Plant Physiol. 2013;161:1645-55.

24. Evans JR, Seemann JR. The allocation of protein nitrogen in the photosynthetic apparatus: costs, consequences and control. In: Brigs WR, editor. Photosynthesis. New York: Alan R. Liss; 1989. p. 183-205.

25. Makino A, Sakuma H, Sudo E, Mae T. Differences between maize and rice in $\mathrm{N}$-use efficiency for photosynthesis and protein allocation. Plant Cell Physiol. 2003:44:952-6.

26. Makino A. Photosynthesis, grain yield, and nitrogen utilization in rice and wheat. Plant Physiol. 2011;155:125-9.

27. Evans JR, Clarke VC. The nitrogen cost of photosynthesis. J Exp Bot. 2019;70: $7-15$.

28. Cheng $\mathrm{L}$, Fuchigami LH. Rubisco activation state decreases with increasing nitrogen content in apple leaves. J Exp Bot. 2000;51:1687-94.
29. Ray D, Sheshshayee MS, Mukhopadhyay K, Bindumadhava H, Prasad TG, Kumar MU. High nitrogen use efficiency in rice genotypes is associated with higher net photosynthetic rate at lower Rubisco content. Biol Plantarum. 2003:46:251-6.

30. Warren CR. The photosynthetic limitation posed by internal conductance to co2 movement is increased by nutrient supply. J Exp Bot. 2004:55:2313-21.

31. Warren CR, Dreyer E, Adams MA. Photosynthesis-Rubisco relationships in foliage of Pinus Sylvestris in response to nitrogen supply and the proposed role of Rubisco and amino acids as nitrogen stores. Trees. 2003;17:359-66.

32. Manter DK, Kerrigan J. A/ci curve analysis across a range of woody plant species: influence of regression analysis parameters and mesophyll conductance. J Exp Bot. 2004:55:2581-8.

33. Ehleringer J, Björkman O. Quantum yields for $\mathrm{CO}_{2}$ uptake in $\mathrm{C} 3$ and $\mathrm{C} 4$ plants dependence on temperature, $\mathrm{CO}_{2}$, and $\mathrm{O}_{2}$ concentration. Plant Physiol. 1977:59:86-90.

34. Mcausland L, Vialet-Chabrand S, Davey P, Baker NR, Brendel O, Lawson T. Effects of kinetics of light-induced stomatal responses on photosynthesis and water-use efficiency. New Phytol. 2016;211:1209-20.

35. Kong F, Deng Y, Zhou B, Wang G, Wang Y, Meng Q. A chloroplast-targeted DnaJ protein contributes to maintenance of photosystem II under chilling stress. J Exp Bot. 2014;65:143-58.

36. Brestic M, Zivcak M, Hauptvogel P, Misheva S, Kocheva K, Yang X, Li X, Allakhverdiev SI. Wheat plant selection for high yields entailed improvement of leaf anatomical and biochemical traits including tolerance to non-optimal temperature conditions. Photosynth Res. 2018;136:245-55.

37. Zhuang K, Kong F, Zhang S, Meng C, Yang M, Liu Z, Wang Y, Ma N, Meng Q. Whirly1 enhances tolerance to chilling stress in tomato via protection of photosystem II and regulation of starch degradation. New Phytol. 2019;221: 1998-2012.

38. Zhang M, Zhang GQ, Kang HH, Zhou SM, Wang W. TaPUB1, a putative E3 ligase gene from wheat, enhances salt stress tolerance in transgenic Nicotiana benthamiana. Plant Cell Physiol. 2017;58:1673-88.

39. Tan W, Meng QW, Brestic M, Olsovska K, Yang X. Photosynthesis is improved by exogenous calcium in heat-stressed tobacco plants. J Plant Physiol. 2011;168:2063-71.

40. Farquhar GD, von Caemmerer S, Berry JA. A biochemical model of photosynthetic $\mathrm{CO}_{2}$ assimilation in leaves of C3 species. Planta. 1980;149: 78-90.

41. Long SP, Bernacchi CJ. Gas exchange measurements, what can they tell us about the underlying limitations to photosynthesis? Procedures and sources of error. J Exp Bot. 2003;54:2393.

42. Bernacchi CJ, Bagley JE, Serbin SP, Ruiz-Vera UM, Rosenthal DM, Vanloocke A. Modelling C3 photosynthesis from the chloroplast to the ecosystem. Plant Cell Environ. 2013;36:1641-57.

43. Naranjo B, Diaz-Espejo A, Lindahl M, Cejudo FJ. Type-f thioredoxins have a role in the short-term activation of carbon metabolism and their loss affects growth under short-day conditions in Arabidopsis thaliana. J Exp Bot. 2016; 67:1951-64

44. Avron M, Gibbs M. Properties of phosphoribulokinase of whole chloroplasts. Plant Physiol. 1974;53:136-9.

45. Sassenrath-Cole GF, Pearcy RW. Regulation of photosynthetic induction state by the magnitude and duration of low light exposure. Plant Physiol. 1994;105:1115-23.

46. Marri L, Zaffagnini M, Collin V, Issakidisbourguet E, Lemaire SD, Pupillo P, et al. Prompt and easy activation by specific thioredoxins of Calvin cycle enzymes of arabidopsis thaliana associated in the gapdh/cp12/prk supramolecular complex. Mol Plant. 2009;2:259-69.

47. Howard TP, Metodiev M, Lloyd JC, Raines CA. Thioredoxin-mediated reversible dissociation of a stromal multiprotein complex in response to changes in light availability. P Natl Acad Sci USA. 2008;105:4056-61.

48. Haake V, Geiger M, Walch-Liu P, Engels C, Zrenner R, Stitt M. Changes in aldolase activity in wild-type potato plants are important for acclimation to growth irradiance and carbon dioxide concentration, because plastid aldolase exerts control over the ambient rate of photosynthesis across a range of growth conditions. Plant J. 1999;17:479-89.

49. Haake V, Zrenner R, Sonnewald U, Stitt M. A moderate decrease of plastid aldolase activity inhibits photosynthesis, alters the levels of sugars and starch and inhibits growth of potato plants. Plant J. 1998;14:147-57.

50. Henkes S, Sonnewald U, Badur R, Flachmann R, Stitt M. A small decrease of plastid transketolase activity in antisense tobacco transformants has 
dramatic effects on photosynthesis and phenylpropanoid metabolism. Plant Cell. 2001;13:535-51.

51. Armbruster U, Carrillo R, Venema K, Pavlovic L, Schmidtmann E, Kornfeld A, et al. Ion antiport accelerates photosynthetic acclimation in fluctuating light environments. Nat Commun. 2014;5:5439.

52. Leakey ADB, Press MC, Scholes JD. High-temperature inhibition of photosynthesis is greater under sunflecks than uniform irradiance in a tropical rain forest tree seedling. Plant Cell Environ. 2003;26:1681-90.

53. Naumburg E, Ellsworth DS. Photosynthetic sunfleck utilization potential of understory saplings growing under elevated $\mathrm{CO}_{2}$ in face. Oecologia. 2000; 122:163-74.

54. Holišová P, Zitová M, Klem K, Urban O. Effect of elevated carbon dioxide concentration on carbon assimilation under fluctuating light. J Environ Qual. 2012:41:1931-8.

55. Kaiser E, Kromdijk J, Harbinson J, Heuvelink E, Marcelis LFM. Photosynthetic induction and its diffusional, carboxylation and electron transport processes as affected by $\mathrm{CO}_{2}$ partial pressure, temperature, air humidity and blue irradiance. Ann Bot. 2017;119:191-205.

56. Kaiser E, Zhou D, Heuvelink E, Harbinson J, Morales A, Marcelis LFM. Elevated $\mathrm{CO}_{2}$ increases photosynthesis in fluctuating irradiance regardless of photosynthetic induction state. J Exp Bot. 2017;68:5629-40.

57. Paradiso R, Buonomo R, Dixon MA, Barbieri G, De Pascale S. Effect of bacterial root symbiosis and urea as source of nitrogen on performance of soybean plants grown hydroponically for bioregenerative life support systems (BLSSs). Front Plant Sci. 2015;6:888.

58. Keino L, Baijukya F, Ng'etich W, Otinga AN, Okalebo JR, Njoroge R, Mukalama J. Nutrients limiting soybean (Glycine max) growth in Acrisols and ferralsols of Western Kenya. PLoS One. 2015;10:12.

59. Takatani N, Ito T, Kiba T, Mori M, Miyamoto T, Maeda SI, Omata T. Effects of high $\mathrm{CO} 2$ on growth and metabolism of Arabidopsis seedlings during growth with a constantly limited supply of nitrogen. Plant Cell Physiol. 2014:55:281-92.

60. Li Y, Gao Y, Xu X, Shen Q, Guo S. Light-saturated photosynthetic rate in high-nitrogen rice (Oryza sativa L.) leaves is related to chloroplastic $\mathrm{CO}_{2}$ concentration. J Exp Bot. 2009;60:2351-60

61. Li Y, Ren B, Ding L, Shen Q, Peng S, Guo S. Does chloroplast size influence photosynthetic nitrogen use efficiency? PLoS One. 2013:8:4

62. Fernández-Crespo E, Scalschi L, Llorens E, García-Agustín P, Camañes G. $\mathrm{NH}_{4}^{+}$protects tomato plants against Pseudomonas syringae by activation of systemic acquired acclimation. J Exp Bot. 2015;66:6777-90.

63. Porra RJ. The chequered history of the development and use of simultaneous equations for the accurate determination of chlorophyll a and b. Photosynth Res. 2002;73:149-56.

64. Bernacchi CJ, Singsaas EL, Pimentel C, Portis AR, Long SP. Improved temperature response functions for models of rubisco-limited photosynthesis. Plant Cell Environ. 2001;24:253-9.

65. Sharkey TD, Bernacchi CJ, Farquhar GD, Singsaas EL. Fitting photosynthetic carbon dioxide response curves for C3 leaves. Plant Cell Environ. 2007:30: 1035-40.

66. Yang X, Liang Z, Lu C. Genetic engineering of the biosynthesis of glycinebetaine enhances photosynthesis against high temperature stress in transgenic tobacco plants. Plant Physiol. 2005;138:2299-309.

67. Cheng F, Zhou YH, Xia XJ, Shi K, Zhou J, Yu JQ. Chloroplastic thioredoxin-f and thioredoxin-m 1/4 play important roles in brassinosteroids-induced changes in $\mathrm{CO}_{2}$ assimilation and cellular redox homeostasis in tomato. $J$ Exp Bot. 2014;65:4335-47.

68. Harrison EP, Willingham NM, Lloyd JC, Raines CA. Reduced sedoheptulose-1,7bisphosphatase levels in transgenic tobacco lead to decreased photosynthetic capacity and altered carbohydrate accumulation. Planta. 1998;204:27-36.

69. Simkin AJ, McAusland L, Headland LR, Lawson T, Raines CA. Multigene manipulation of photosynthetic carbon assimilation increases $\mathrm{CO}_{2}$ fixation and biomass yield in tobacco. J Exp Bot. 2015;66:4075-90

70. Strand A, Hurry V, Henkes S, Huner N, Gustafsson P, Gardeström P, Stitt M. Acclimation of Arabidopsis leaves developing at low temperatures. Increasing cytoplasmic volume accompanies increased activities of enzymes in the Calvin cycle and in the sucrose-biosynthesis pathway. Plant Physiol. 1999;119:1387-98.

\section{Publisher's Note}

Springer Nature remains neutral with regard to jurisdictional claims in published maps and institutional affiliations.

Ready to submit your research? Choose BMC and benefit from:

- fast, convenient online submission

- thorough peer review by experienced researchers in your field

- rapid publication on acceptance

- support for research data, including large and complex data types

- gold Open Access which fosters wider collaboration and increased citations

- maximum visibility for your research: over $100 \mathrm{M}$ website views per year

At BMC, research is always in progress.

Learn more biomedcentral.com/submissions 